\title{
Comunicación alternativa para la transformación de los pueblos indígenas y el eslabón Proaño
}

Alternative communication for the transformation of indigenous peoples and the Proaño link

Comunicação alternativa para a transformação dos povos indígenas e o elo Proaño

\author{
Julio Adolfo BRAVO MANCERO \\ Universidad Nacional de Chimborazo / jbravo@unach.edu.ec \\ Fermin GALINDO ARRANZ \\ Universidad de Santiago de Compostela / fermin.galindo@usc.es \\ Carlos LARREA NARANJO \\ Universidad Nacional de Chimborazo / carlos.larrea@unach.edu.ec \\ Ramiro RUALES PARREÑO \\ Universidad Nacional de Chimborazo / rruales@unach.edu.ec
}

Chasqui. Revista Latinoamericana de Comunicación

N. ${ }^{\circ}$ 146, abril-julio 2021 (Sección Monográfico, pp. 93-112)

ISSN 1390-1079 / e-ISSN 1390-924X

Ecuador: CIESPAL

Recibido: 02-12-2020/Aprobado:05-02-2021 


\title{
Resumen
}

En este artículo se investiga y comprueba cómo Leonidas Proaño usó la comunicación alternativa orientada al cambio social de las comunidades indígenas del Ecuador en: acciones colectivas, difusión en medios tradicionales (escritos y hablados), educación popular y aplicación de métodos rigurosos de recogida de información. Se empleó una metodología mixta, cualitativa y cuantitativa, a través de la revisión documental, análisis crítico del discurso y entrevistas. Se observaron 2.482 contenidos de cinco medios impresos, 389 guiones del programa radiofónico Hoy y mañana, 72 discursos y cuatro libros del período 1938-1988. De ellos, 1.295 documentos estuvieron vinculados con el objeto de estudio, en 327 ediciones de impresos, 85 emisiones radiales, 72 discursos y otros textos.

Palabras clave: Leonidas Proaño; acción colectiva; medios tradicionales; educación popular; cambio social

\begin{abstract}
This article investigates and verifies how Leonidas Proaño used alternative communication oriented to social change of Ecuador's indigenous communities in: collective actions; broadcast in traditional media (written and spoken); popular education; and, application of rigorous methods of information collection. A mixed, qualitative and quantitative methodology was used through documentary review, critical speech analysis and interviews. There were 2.482 content from five print media, 389 scripts from the radio show Today and Tomorrow, 72 speeches and four books from the period between 1938 and 1988. Of these, 1,295 documents were linked to the subject-matter of the study, in 327 editions of prints, 85 radio broadcasts, 72 speeches and other texts.
\end{abstract}

Key words: Leonidas Proaño; collective action; traditional media; popular education; social change

\section{Resumo}

Este artigo investiga e verifica como Leônidas Proaño usou a comunicação alternativa orientada para a mudança social das comunidades indígenas do Equador em: ações coletivas; transmitido em mídia tradicional (escrito e falado); educação popular; e, aplicação de métodos rigorosos de coleta de informações. Utilizou-se metodologia mista, qualitativa e quantitativa por meio de revisão documental, análise de fala crítica e entrevistas. Foram 2.482 conteúdos de cinco mídias impressas, 389 roteiros do programa de rádio Hoje e Amanhã, 72 discursos e quatro livros do período entre 1938 e 1988. Destes, 1.295 
documentos foram vinculados ao tema do estudo, em 327 edições de gravuras, 85 transmissões de rádio, 72 discursos e outros textos.

Palavras-chave: Leonidas Proaño; ação coletiva; Mídia tradicional; educação popular; mudança social

\section{Introducción y marco teórico}

En este artículo se reflexiona sobre el uso de la comunicación alternativa sostenida por Leonidas Proaño - como una herramienta para el cambio social de los indígenas del Ecuador, que en su mayoría vivían en la ruralidad, en situaciones de injusticia, marginación, exclusión y dominación. Se estableció como pregunta de investigación ¿de qué manera la comunicación alternativa de Proaño registró información sobre la realidad sociocultural, la difundió en medios tradicionales (hablados y escritos), y motivó la acción y cambio social de las comunidades indígenas, durante cincuenta años? El objetivo principal fue identificar la utilización de la comunicación alternativa para la transformación. La metodología fue de tipo mixta: cualitativa y cuantitativa. Como técnicas se utilizaron la revisión documental de 327 ediciones de los impresos Granitos de Trigo, La Verdad, Mensaje, Jatari Campesino y Jatari, 389 guiones del programa Hoy y mañana, emitido por Escuelas Radiofónicas Populares del Ecuador (ERPE), el análisis crítico del discurso de 1.295 contenidos, la entrevista a 11 expertos en la temática, 72 discursos realizados cuando Proaño dejó el obispado de Riobamba y cuatro libros que recogen los procesos de capacitación, formación y debate.

Con esta aproximación se buscó establecer de qué manera la comunicación alternativa de Proaño se enfocó en: 1. Acciones colectivas; 2. Medios tradicionales; 3. Educación popular; y, 4. Uso de métodos (ver, juzgar y actuar, teología de los signos de los tiempos, investigación acción participativa, teoría de la acción comunicativa para recoger información). Buscaba a) Identificar las condiciones en las que habitaban los indígenas en sus desplazamientos, audiencias, reuniones y eventos formativos dirigidos a obreros, jóvenes, mujeres y adultos mayores. b) Difundir la realidad y la puesta en marcha de un proyecto para la modificación de las condiciones del "hombre concreto". c) Implementar un proceso de alfabetización/capacitación usando la educación popular. d) Aplicar técnicas e instrumentos metodológicos para obtener información de primera mano y utilizarla en acciones comunitarias, periodísticas y educativas. De esta manera se pudo evidenciar cómo lo alternativo, desde la praxis, sirvió al Proaño comunicador para recuperar los valores humanos de los excluidos y empobrecidos (indígenas), la toma de conciencia frente a sus situaciones sociales, políticas, económicas y culturales y para el desarrollo mediante procesos comunicativos. 
Aunque los estudios indigenistas en las últimas décadas se han reivindicado y fortalecido, De Hoyos (1949, p. 180) identifica el inicio de los trabajos formales sobre este tema, en el último tercio del siglo XIX "como consecuencia del triunfo del movimiento antiesclavista”. Sin embargo, en los 9o, la importancia se incrementa porque las condiciones de vida, de estudio, de economía, sociales y de reivindicación toman un giro. La reafirmación y el redescubrimiento de la identidad han motivado que el movimiento social, desde la propuesta de González (2004, p. 140), ha logrado "la resistencia por la autonomía y la percepción como colectivo de variados aspectos culturales del movimiento indígena". "La lucha del movimiento indígena en las últimas décadas se desarrolla en el marco de la recuperación o reafirmación de sus identidades" (Bravo, Mora, \& Galindo, 2019, p. 57).

El carácter del presente trabajo ha rescatado, identificado y analizado los aprendizajes y la práctica de los actos comunicativos, en acciones colectivas, periodísticas y educativas, usando enfoques metodológicos como soporte para espacios de diálogo-reflexión con indígenas, sindicalistas, jóvenes y mujeres. Escenarios en los cuales los integrantes de una agrupación o una comunidad excluida recopilan y analizan información, e intervienen sobre problemas comunes para hallar soluciones que les permitan transformar esa realidad (Selener citado en Bravo, 2019). La aproximación teórica frente a su vínculo con la comunicación alternativa traza su enfoque desde una consolidada tradición académica: De Hoyos (1949), Freire (1970), Proaño (1974, 1976 y 1980), Habermas (1976), Lewis (1995), Castillo (1997), Bellini (2009), Corrales y Hernández (2009), Silva (2009), Sager (2011), Barranquero y Sáez (2012), Browne-Sartori y CastilloHinojosa (2013), Pérez (2016), Van Dijk (2016), Deliyore-Vega (2018), Alcántara, Sampaio y Uriarte (2018), Bravo, Mora y Galindo (2019). Las propuestas iniciales de comunicación alternativa aún están siendo estudiadas a profundidad por la academia ecuatoriana y latinoamericana. Existen investigaciones posteriores a Proaño publicadas en la región y en España: Invisibilización de la comunicación alternativa (Sáez, 2009); El acercamiento a la alternancia de los medios y la participación importante, en estos días (Corrales \& Hernández, 2009); Conceptualizaciones de lo alternativo (Sager, 2011); Teoría Crítica de la Comunicación Alternativa, el legado de Paulo Freire y Antonio Gramsci (Barranquero \& Sáez, 2012); Empoderamiento y participación en tiempos de violencia (Mendívil, Racedo, Meléndez \& Rosero, 2015); La radio universitaria en España: comunicación alternativa de servicio público para la formación (MartínPena \& Aguaded, 2016); Comunicación alternativa: una opción para los jóvenes (Pérez, 2016); Trascendencia de lo alternativo para la inclusión social (DeliyoreVega, 2018); La comunicación alternativa entre lo digital y lo decolonial (Kaplún, 2019); Tecnologías de la Información (Almanza, Mesa, Naranjo, Soler, Ordóñez, \& Suárez, 2019).

Leonidas Proaño ejerció la comunicación popular, comunicación política, comunicación educativa, comunicación comunitaria y comunicación 
liberadora. Cada una en el ejercicio del sacerdocio, primero, y segundo, del obispado; entre Ibarra y Riobamba, en los nueve medios que fundó, como se explica a continuación: en los cientos de folletos, cuadernos de debate, volantes y manuales de formación dirigidos a estudiantes, obreros, seglares, mujeres, adultos y niños; $y$, en las organizaciones de indígenas, centros de formación como Tepeyac, Frente de Solidaridad por Chimborazo e instituciones de derechos humanos. Sus acciones mejoraron las condiciones de vida de los indígenas, en su mayoría empobrecidos (Bravo \& Galindo, 2020). Esas propuestas, en una parte anteceden a las iniciativas de Luis Ramiro Beltrán (comunicología liberadora) (citado en Olmedo Salar, 2014) prologada por Manuel Chaparro, que coincidió con el despertar de los programas de desarrollo apartados de la idea de asistencialismo; $y$, otras que concuerdan en la cronología, con la visión de progreso. La educación liberadora de Paulo Freire también está unida a un mismo cordón umbilical: la alfabetización usando medios masivos (como la radio en Ecuador).

La comunicación alternativa propone el cambio de la sociedad, evidente en actividades mediáticas como radios y periódicos populares (Pensa \& Roitman, 2005), y en el uso de folletería, espacios para el diálogo como asambleas populares, lugares físicos de información como las carteleras, entre otros. La premisa de que surge de y para la comunidad, orienta la transformación (Lewis, 1995, p. 12). "Propone lo alterno a los medios tradicionales, es decir, a los más utilizados", como una nueva opción generadora de nuevas realidades. Este proceso se visibiliza en la riqueza documental como resultado investigativo; "no es una actividad en sí, dotada de una finalidad que se agota en sí misma", asegura Aguirre (citado en Simpson, 1986, p. 61); lo alternativo identifica una tarea global con fines de toma de conciencia, cambio de actitud y modificación de la vida, que se logra siguiendo tres pasos: 1. Elaboración; 2. Difusión; 3. Lectura (Castillo, 1997). La comunicación alternativa posibilitó el cambio de los indígenas ecuatorianos y abrió surcos para su desarrollo.

\section{El eslabón de Proaño, contexto histórico y comunicativo}

Leonidas Proaño Villalba nació en San Antonio de Ibarra, Ecuador, el 29 de enero de 1910. Fue sacerdote y capellán en su lugar natal entre 1936 y 1954, obispo de la Diócesis de Riobamba (1954-1985), y en la etapa final de su vida lideró la Pastoral Indígena. Participó, a partir de las experiencias con los campesinos, en el Concilio Vaticano II. En principio, se identifica solo la relación de su acción con la religión, sin embargo, va más allá cuando se evidencian actividades laicas transformadoras. Por ejemplo, el trabajo con los obreros o con los sectores empobrecidos del campo y de la ciudad (Proaño, 1980).

Las jornadas de lucha a favor de la transformación fueron interminables, describe Luciano Bellini (1988) que recopiló y publicó en un libro sus discursos y otras aportaciones. Lo alternativo en el acto comunicacional, evidente en 
acciones colectivas, educación popular y uso de metodología privilegiaba lo local. Los ideales de liberación de los indios fueron praxis y se difundieron en los medios: Excélsior (1934), Granitos de Trigo (1938), El Cuadrilátero (1942), La Verdad (1944), Mensaje (1955), ERPE (1962), Jatari Campesino (1965), Jatari (1971) y Promoción (1980). Su arenga se orientó desde el contrapoder y lo contestatario. La contrahegemonía marcó "los elementos para la construcción de una conciencia política autónoma en las diversas clases y sectores populares" (Valenzuela, Murua, \& Poblete, 2014, p. 2). Lo educativo siguió la hoja de ruta de Paulo Freire (1970) a través de la Pedagogía del Oprimido que en líneas generales coincidía con la propuesta de Leonidas Proaño: formar para la vida, solucionar los problemas, asociarse, reivindicar los derechos colectivos y humanos y dejar de ser explotados.

La obra de Proaño desde la comunicación popular, comunitaria y alternativa ha estado invisibilizada durante décadas. Sus contribuciones desde lo comunicológico significan contemporaneidad, inclusive con el pensamiento crítico de la Escuela Latinoamericana de la Comunicación (Elacom), y por otro lado, en la teorización de una rica praxis en territorio de los indígenas ecuatorianos, tomada como ejemplo para otros países de la región. Estas últimas afirmaciones justifican el eslabón Proaño entre la comunicación popular y comunitaria, y la comunicación alternativa. Representan una antesala a otras miradas de una acción colectiva: de diálogo, escucha e intervención; de toma de conciencia y cambio de actitud para mejorar la vida de los humildes por medio de la participación colectiva.

\section{Metodología}

La presente investigación se derivó de la Tesis Doctoral del autor para la Universidad de Santiago de Compostela. Se usó metodología mixta: cualitativa, como categoría de diseño de investigación que prioriza la comprensión y el sentido, este procedimiento observa intenciones, motivaciones, expectativas, razones y creencias de las personas (Monje, 2011); y, cuantitativa, que utiliza la medición estadística para precisar las observaciones, análisis e interpretación de resultados (Gómez, Deslauriers, \& Piedrahita, 1990). Como técnicas se utilizaron la revisión documental, el análisis crítico del discurso y la entrevista.

La muestra corresponde a 1.295 contenidos difundidos de forma impresa y hablada; 72 discursos, durante medio siglo (1938-1988). La información corresponde a jornadas de capacitación, discusión y difusión, mediada por la comunicación alternativa.

\subsection{Revisión documental}

Representa el contenido de forma distinta a la original, ya que es un trabajo intelectual que centra al investigador en el análisis e interpretación de los datos 
para construir un producto y difundirlo. "Debe considerarse exclusivamente como descripción del contenido y no como descripción formal" (Clauso, 1993, p. 11). "Es un tema complejo en esencia, por cuanto posee aristas de tipo lingüístico, psicológico-cognitivo, documental, social e informacional propiamente dicho" (Peña \& Pirela, 2007, p. 56). La revisión documental cumple con los requerimientos de recolección, procesamiento e interpretación de los datos (Castro, 2017).

Tabla 1. Tipo, nombre y año de las publicaciones sobre los que se realizó la revisión documental y el análisis crítico del discurso.

\begin{tabular}{|l|l|c|}
\hline \multicolumn{1}{|c|}{ Tipo/Medio } & \multicolumn{1}{|c|}{ Documento } & Año De Creación \\
\hline Impreso & Periódico Granitos de Trigo & 1938 \\
\hline Impreso & Bisemanario La Verdad & 1944 \\
\hline Impreso & Revista Mensaje & 1954 \\
\hline Radio & ERPE. Programa Hoy y mañana & 1962 \\
\hline Impreso & Jatari Campesino & 1965 \\
\hline Impreso & Jatari & 1971 \\
\hline Libro & Concientización, evangelización, política & 1974 \\
\hline Libro & Evangelio subversivo & 1977 \\
\hline Oral & Discursos & 1985 \\
\hline Libro & Abriendo surcos indígenas 1 & 2011 \\
\hline Libro & Abriendo surcos indígenas 2 & 2011 \\
\hline
\end{tabular}

Fuente: Elaboración propia

Repositorio: Fondo Documental Diocesano

La revisión tuvo cinco etapas (Figura 1): 1. En el Fondo Documental Diocesano de Riobamba donde reposan 26 ediciones de Granitos de Trigo, 62 de La Verdad, 94, de Mensaje, 16 de Jatari Campesino y 55 Jatari, 389 guiones del programa Hoy y mañana, ERPE y, los libros analizados (Tabla 1). 2. Recuperación y recogida de información con el instrumento matriz de análisis, diseñada por los investigadores, que desde la perspectiva de Gabriel Galdón (2002, p. 70) constituye la función preparatoria que entrega datos de primera mano. 3. La jerarquización de la temática que comprende la función crítico-verificadora, también referida por el profesor Galdón, que es la comprobación de la exactitud de los hechos usando otras fuentes y su clasificación según criterios de relevancia y significación que equivale a establecer el nivel de confiabilidad de la información (Bravo, 2011). 4. Selección y valoración, para Galdón es la función completiva que contextualiza los hallazgos y los clasifica en orden de importancia; 5. Discusión y presentación de resultados, mediante el contraste con la fundamentación teórica. 
Figura1. Etapas del proceso de análisis de contenido de la revista Mensaje

1. Trabajo en el Fondo Documental

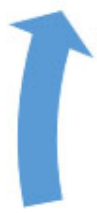

\section{Discusión y presentación de resultados}

\section{Recuperación y} recogida de información

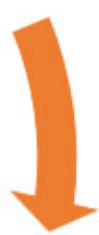

3. Jerarquización de temas

\section{Selección y valoración}

Fuente: Elaboración propia

En su trabajo en el campo, audiencias, reuniones, conferencias, discursos y en medios escritos y hablados en los que Proaño expresó sus ideas a través de géneros editoriales, artículos, notas informativas, crónicas dialogadas y radiorevistas para motivar la toma de conciencia sobre la importancia del cambio social. La ficha utilizada fue diseñada de tal forma que se evidencie en una columna el nivel semántico ¿qué dice? y el nivel pragmático ¿cómo lo dice? El trabajo presentó una primera referencia de los ejes temáticos presentes en los contenidos que luego fueron cribados para jerarquizarlos según el nexo con la comunicación alternativa; para la selección y valoración se emplearon tablas para facilitar el manejo y la presentación de los resultados.

La organización de la documentación, según la publicación, el texto y el contexto, sirvió para analizar la forma en la que la comunicación alternativa identificada en las etapas (acciones colectivas, difusión en medios tradicionales, educación popular y lo metodológico) y el vínculo con los actos comunicativos (escucha durante las visitas, diálogo como herramienta de los encuentros y difusión usando la radio y la prensa), orientaba a la modificación de las condiciones de vida de los habitantes en situaciones de exclusión y pobreza. 


\subsection{Análisis Crítico de Discurso (ACD)}

Para Browne y Castillo (2013) permite comprender la construcción social de la realidad a partir de los tratamientos noticiosos. Cepeda, Mujica, Pilleux y Poblete (1999) insisten en que identifican cómo los textos orales y escritos se desenvuelven en la sociocultura. El ACD considera al lenguaje como "producto de la organización lingüística en todos los niveles de análisis" (Fowler, 1985, p. 80). Fairclough (1995) indica que comprende la descripción a escala textual y contextual. Van Dijk (2016, p. 204) expresa cómo el abuso de poder y la desigualdad social se representan, reproducen, legitiman y resisten en el texto y en el habla para contextos sociales y políticos.

Urra y Sandoval (2018, p. 200) sostienen que "se diferencia de los otros enfoques porque no solo describe e interpreta los discursos en sus contextos, sino que ofrece una explicación del por qué y cómo el discurso opera”. El ACD se desarrolló durante tres momentos (Figura 2).

Figura 2: Fases del análisis crítico del discurso
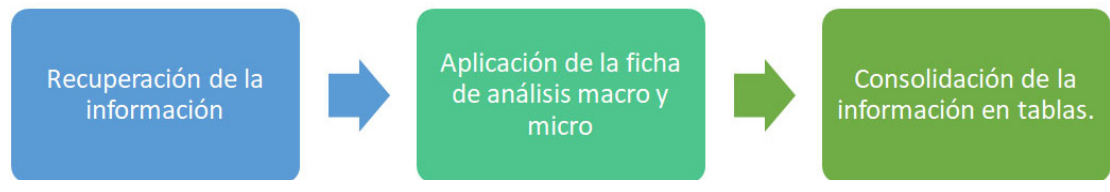

Fuente: Elaboración propia

El ACD empezó con la recuperación de 1.295 contenidos en los que existe evidencia del trabajo con comunicación alternativa. Análisis: la ficha distribuyó los elementos: a) Encabezado: información del impreso, guion radiofónico, discurso/homilía, fecha, tipo de contenido, observaciones. b) Nivel micro: uso del lenguaje, discurso e interacción verbal (¿qué dice?). c) A quién está dirigido: grupo, estructura social, acciones-procesos. d) Cognición-social. e) Nivel macro (¿cómo lo dice?). La información fue codificada, cuantificada y cualificada para presentarla en textos, tablas y representaciones gráficas, como aparecen en los resultados.

\subsection{Entrevista no estructurada}

Ccon el criterio de cinco expertos se comprendió la dimensión comunicativa alternativa para el cambio social; permitió manejar los datos con flexibilidad. Calderón y Alvarado (2011) afirman que el contenido, orden, profundidad y las interrogantesformuladas por el entrevistador son las que permitiránla obtención de información útil para despejar dudas sobre lo investigado. Folgueiras (2016, p. 3) pone énfasis en que "la entrevista se construye simultáneamente a partir de las respuestas de la persona entrevistada. Las respuestas son abiertas y sin 
categorías de respuesta establecidas a priori”. Feria, Matilla y Mantecón (2020) destacan la libertad (entrevistado y entrevistador) para preguntar y responder. Mientras Trindade (2016) advierte que la naturalidad permite obtener datos en un ambiente distendido. En la selección de los expertos se consideró la relación con Proaño, el dominio de la temática y la experiencia en el ejercicio comunicacional. Las respuestas se agruparon desde la arista comunicativa y sirvieron para orientar este trabajo.

Las entrevistas se realizaron entre julio de 2018 y noviembre de 2019. Los especialistas tuvieron vínculos: periodísticos, de comunicación alternativa y religiosos; así, Juan Pérez, director de Escuelas Radiofónicas Populares del Ecuador impulsó desde su juventud, junto con Proaño, la radio educativa como una opción para la transformación social; Patricio Muñoz y Rubén Viñán se ocuparon de la comunicación alternativa en las comunidades indígenas y campesinas, convertida en el eje para la toma de conciencia, cambio de actitud y desarrollo colectivo; Pedro Torres, integrante del equipo de evangelización, acompañó las jornadas de debate sobre la realidad.

\section{Resultados}

\subsection{Análisis crítico del discurso}

Los datos que contienen las tablas (acciones colectivas realizadas por Leonidas Proaño; difusión en medios tradicionales (escritos y hablados), discursos; educación popular; métodos para la recogida de información) fueron recopilados usando matrices para la revisión documental, el ACD y la entrevista. En el ACD se aplicaron matrices individuales por eje de estudio. El encabezado ubicó el medio, la fecha y el lugar de publicación/difusión enmarcado en lo temporal y espacial. En la parte esencial se siguió la propuesta metodológica de Van Dijk (2016); el primer casillero se dedicó al nivel micro, dividido de tal manera que presente datos vinculados con uso del lenguaje, discurso e interacción verbal; el segundo, rescató las categorías y subcategorías discursivas; el tercero, el direccionamiento de los mensajes; el cuarto, el nivel macro que reveló la fuerza discursiva. Y para el caso de las entrevistas, la matriz ubicó las similitudes desde las perspectivas de los especialistas. Las respuestas se agruparon por categorías para recrear de mejor forma los resultados. 
Tabla 2. Acciones colectivas realizadas por Leonidas Proaño

\begin{tabular}{|l|l|l|l|}
\hline \multicolumn{1}{|c|}{ Año/actividad } & \multicolumn{1}{c|}{ Acto comunicativo } & \multicolumn{1}{c|}{ Reflexión } & \multicolumn{1}{c|}{ Acción colectiva } \\
\hline $\begin{array}{l}\text { 1942, formación de } \\
\text { la Juventud Obrera } \\
\text { Católica (JOC). }\end{array}$ & $\begin{array}{l}\text { Escucha-diálogo, talleres } \\
\text { de capacitación }\end{array}$ & $\begin{array}{l}\text { Toma de conciencia frente a } \\
\text { la explotación. }\end{array}$ & $\begin{array}{l}\text { Organización para } \\
\text { fortalecer las actividades. }\end{array}$ \\
\hline $\begin{array}{l}\text { 1955, trabajo de } \\
\text { campo. }\end{array}$ & $\begin{array}{l}\text { Escucha-diálogo, } \\
\text { recorridos }\end{array}$ & $\begin{array}{l}\text { Actitud frente a la } \\
\text { marginación y exclusión. }\end{array}$ & $\begin{array}{l}\text { Plan para incorporación al } \\
\text { indio a la vida civilizada. }\end{array}$ \\
\hline $\begin{array}{l}\text { 1956, parcelación de } \\
\text { tierras. }\end{array}$ & $\begin{array}{l}\text { Escucha-diálogo, toma } \\
\text { de conciencia-cambio de } \\
\text { actitud }\end{array}$ & $\begin{array}{l}\text { Los hacendados explotaban } \\
\text { a los indígenas. }\end{array}$ & $\begin{array}{l}\text { Parcelación de las } \\
\text { haciendas de la Diócesis. } \\
\text { Inicio de la Reforma Agraria } \\
\text { en Ecuador. }\end{array}$ \\
\hline $\begin{array}{l}\text { 1959, ejecución de la } \\
\text { Misión Andina. }\end{array}$ & $\begin{array}{l}\text { Escucha-diálogo- } \\
\text { formación campesina. }\end{array}$ & $\begin{array}{l}\text { En lo rural las condiciones } \\
\text { de vida eran deplorables. }\end{array}$ & $\begin{array}{l}\text { Mejoramiento del sector } \\
\text { rural. }\end{array}$ \\
\hline $\begin{array}{l}\text { 1958, Granja Escuela } \\
\text { Tepeyac. }\end{array}$ & $\begin{array}{l}\text { Formación campesina, } \\
\text { talleres. }\end{array}$ & $\begin{array}{l}\text { Para que haya desarrollo } \\
\text { rural se necesitaba una } \\
\text { instancia dedicada al trabajo } \\
\text { colectivo. }\end{array}$ & $\begin{array}{l}\text { Creación de la Granja } \\
\text { Escuela para actividades } \\
\text { formativas. }\end{array}$ \\
\hline $\begin{array}{l}\text { 1962-1965, Concilio } \\
\text { Vaticano II. }\end{array}$ & $\begin{array}{l}\text { Escucha-diálogo, talleres } \\
\text { ecuménicos, preparación. }\end{array}$ & $\begin{array}{l}\text { La iglesia necesitaba un } \\
\text { cambio. }\end{array}$ & $\begin{array}{l}\text { Modificación de la } \\
\text { estructura orgánica. }\end{array}$ \\
\hline 1974, Acciones en Iltús. & Escucha-diálogo. & $\begin{array}{l}\text { La explotación se mantenía } \\
\text { en las haciendas }\end{array}$ & $\begin{array}{l}\text { Organización para afrontar } \\
\text { la explotación. }\end{array}$ \\
\hline $\begin{array}{l}\text { 1974, Definición del } \\
\text { hombre concreto. }\end{array}$ & $\begin{array}{l}\text { Escucha-diálogo, visitas } \\
\text { al campo }\end{array}$ & $\begin{array}{l}\text { Era necesario conocerse } \\
\text { para conocer a los demás. }\end{array}$ & $\begin{array}{l}\text { Definición de las } \\
\text { características de los } \\
\text { sujetos. }\end{array}$ \\
\hline
\end{tabular}

Fuente: Elaboración propia

La tabla clasifica algunas de las acciones colectivas entre 1938-1988, en las que se evidencian actos de comunicación alternativa para el cambio social. Sus actuaciones lo llevaron a recibir el calificativo de Obispo Rojo (Rubén Viñán, entrevista personal N. ${ }^{\circ}$, enero de 2018). Con la intervención por medio de lo comunicacional (escucha-diálogo, talleres, recorridos, mingas, jornadas de capacitación, entre otros), los indígenas y mestizos, del campo y de los sectores suburbanos, iniciaron procesos participativos orientados a la transformación, y a la búsqueda de libertad, justicia y solidaridad (Alcántara \& Sampaio, 2013).

La aplicación de la comunicación alternativa fue evidente en la organización obrera, la reivindicación de los indígenas para que alcanzaran la categoría de seres humanos, la entrega de tierras para trabajar y subsistir, condiciones saludables de habitación en el campo, la formación (promotores para el desarrollo rural, líderes campesinos, referida por Proaño en: revista Mensaje, periódicos Jatari Campesino y Jatari) y la transformación de la Iglesia a partir del Concilio. 
Tabla 3. Difusión en medios tradicionales (escritos y hablados)

\begin{tabular}{|l|l|l|}
\hline \multicolumn{1}{|c|}{ Año/tipo/medio } & \multicolumn{1}{|c|}{ Titular } & \multicolumn{1}{c|}{ Orientación alternativa } \\
\hline $\begin{array}{l}\text { 1944, bisemanario La } \\
\text { Verdad de Ibarra. }\end{array}$ & $\begin{array}{l}\text { El indio } \\
\text { ecuatoriano }\end{array}$ & $\begin{array}{l}\text { Por primera vez realiza la exposición de la realidad indígena, solicita } \\
\text { intervención de la Asamblea Nacional. }\end{array}$ \\
\hline $\begin{array}{l}\text { 1960, revista Mensaje } \\
\text { de Riobamba. }\end{array}$ & $\begin{array}{l}\text { Reivindicación de } \\
\text { la mujer }\end{array}$ & $\begin{array}{l}\text { Con procesos alternativos de formación se logró el cambio; aprender } \\
\text { un oficio (costura, panadería, pastelería) para no ser empleada } \\
\text { doméstica, sino manejar cajas comunitarias y cooperativas agrícolas. }\end{array}$ \\
\hline $\begin{array}{l}\text { 1962, radio programa } \\
\text { Hoyy mañana, ERPE. }\end{array}$ & $\begin{array}{l}\text { Procesos } \\
\text { agroecológicos }\end{array}$ & $\begin{array}{l}\text { Respeto por la tierra y por el ser humano mediante la agricultura } \\
\text { limpia que genere productos saludables que protejan la vida. }\end{array}$ \\
\hline $\begin{array}{l}\text { 1960, revista Mensaje } \\
\text { de Riobamba. }\end{array}$ & $\begin{array}{l}\text { La asociatividad } \\
\text { como camino }\end{array}$ & $\begin{array}{l}\text { El Centro de Estudios y Acción Social sirvió para fortalecer el } \\
\text { desarrollo local y para impulsar la capacitación cooperativista y } \\
\text { asociativa. }\end{array}$ \\
\hline $\begin{array}{l}\text { 1971, periódico Jatari } \\
\text { mefensa del } \\
\text { moyy mañana, ERPE. }\end{array}$ & $\begin{array}{l}\text { La atención y cuidado del hogar, construcción de letrinas, como a } \\
\text { partir de los productos naturales combatir plagas, adecentamiento } \\
\text { de los ambientes del hogar, construcción de casas saludables, diseño } \\
\text { y confección de ropa, lectura y escritura. }\end{array}$ \\
\hline $\begin{array}{l}\text { 1980, informe } \\
\text { Derechos Humanos. }\end{array}$ & $\begin{array}{l}\text { La detención de 17 obispos, jóvenes, mujeres, sindicalistas y obreros } \\
\text { durante una jornada de capacitación en el Hogar Santa Cruz, } \\
\text { destinado a la formación y capacitación, fue explicada como una } \\
\text { actividad terrorista por el gobierno del Ecuador. Proaño señaló que el } \\
\text { evangelio es subversivo, porque alerta a la gente a dejar la pasividad. }\end{array}$ \\
\hline
\end{tabular}

Fuente: Elaboración propia

Lo expresado (Tabla 3) identifica los aspectos considerados para el manejo de contenidos, orientado al cambio social desde lo alternativo. Respondían a agendas propias y en distintas épocas, pero, muestran un abanico diferente al tradicional. Los abordajes vinculados con la protección de derechos, la construcción de ciudadanía, la formación agroecológica, el saneamiento ambiental y el aprendizaje de un oficio, convirtieron a los medios en espacios de doble vía para la preparación de las personas para afrontar su cotidianidad.

Tabla 4. Educación popular

\begin{tabular}{|l|l|l|}
\hline Fecha/tipo/medio & Publicación & Situación alternativa \\
\hline 1962, revista Mensaje & $\begin{array}{l}\text { Reporteros indígenas y } \\
\text { populares }\end{array}$ & $\begin{array}{l}\text { Encargados de la difusión de la información de su } \\
\text { comunidad, mediante cartas o de forma presencial. }\end{array}$ \\
\hline $\begin{array}{l}\text { 1965, periódico Jatari } \\
\text { Campesino }\end{array}$ & $\begin{array}{l}\text { Periodismo } \\
\text { especializado en cartas }\end{array}$ & $\begin{array}{l}\text { Publicación de misivas desde todo el Ecuador; los } \\
\text { alfabetizados contaban hechos como "la alfabetización } \\
\text { les devolvió la vista", leer y escribir equivale a "saber } \\
\text { caminar". }\end{array}$ \\
\hline $\begin{array}{l}\text { 1970, programa Hoyy } \\
\text { mañana, ERPE }\end{array}$ & Fiesta de la lectura & $\begin{array}{l}\text { Los alfabetizados aprobaban los módulos con danza, } \\
\text { música autóctona, arte y pintura. }\end{array}$ \\
\hline $\begin{array}{l}\text { 1971, periódico Jatari } \\
\text { 1985, Discurso a jóvenes } \\
\text { de Loja }\end{array}$ & Atención a la familia & $\begin{array}{l}\text { Este contenido esboza estrategias para las actividades } \\
\text { cotidianas de las mujeres. }\end{array}$ \\
\hline
\end{tabular}

Fuente: Elaboración propia 
La Tabla 4 agrupa los resultados que orientan la educación. La formación de reporteros indígenas es considerada un hecho inédito en Latinoamérica; eran la voz de lo que ocurría en sus comunidades. Destaca la fiesta de la lectura que puede afirmarse como otro hito en la rendición de exámenes en la alfabetización. La difusión de cartas enviadas por los alfabetizados, un tercer aspecto que merece relevancia dentro de lo alternativo como ejercicio de transformación.

Tabla 5. Métodos para la recogida de información

\begin{tabular}{|l|l|}
\hline Método & Operatividad \\
\hline Ver-juzgar-actuar & $\begin{array}{l}\text { Identificación de problemas de la realidad, toma de posición, búsqueda } \\
\text { del cambio general y grupal. }\end{array}$ \\
\hline Teología de los signos de los tiempos & $\begin{array}{l}\text { Discernimiento de los signos que traen los tiempos, diálogo conjunto } \\
\text { frente a los signos, construcción de propuestas participativas. }\end{array}$ \\
\hline Investigación Acción Participativa (IAP) & $\begin{array}{l}\text { Identifica aspectos relacionados con la realidad, reflexión para la } \\
\text { transformación, toma de decisiones comunitarias. }\end{array}$ \\
\hline Teoría de la Acción Comunicativa & $\begin{array}{l}\text { Identifica los sujetos y sus problemas, interrelaciones, interacciones e } \\
\text { intermediaciones, entendimiento e intervención. }\end{array}$ \\
\hline
\end{tabular}

Fuente: Elaboración propia

La Tabla 5 organiza, clasifica y describe la operatividad de los cuatro métodos aplicados en acciones colectivas; sirvieron para la difusión en medios y en actividades de educativas. Con ellos desarrolló el acercamiento, diálogoescucha y toma de decisiones. Con los resultados de la aplicación metodológica construyó planes que fueron visibles a partir de los años 70, cuando tuvieron impulso con financiamiento extranjero.

\subsection{Entrevistas}

Explicación de la operatividad

Tabla 6. Similitudes del trabajo de comunicación alternativa desde los expertos

\begin{tabular}{|l|l|l|}
\hline ENTREVISTADO & $\begin{array}{l}\text { Categoría 2 } \\
\text { Interrelación con la gente }\end{array}$ & $\begin{array}{l}\text { Categoría 3 } \\
\text { Interlocutor }\end{array}$ \\
\hline Juan Pérez & $\begin{array}{l}\text { En sus salidas al campo, los fines } \\
\text { de semana, escuchaba-dialogaba- } \\
\text { reflexionaba. Le preocupaba la } \\
\text { realidad de vida. }\end{array}$ & $\begin{array}{l}\text { Rompió la barrera del idioma modos para comprender } \\
\text { lo que en el campo o en su despacho le contaban los } \\
\text { indígenas. Jamás menospreciaba a nadie. }\end{array}$ \\
\hline Patricio Muñoz & $\begin{array}{l}\text { Es uno de los ejes claves para } \\
\text { erradicar la discriminación; } \\
\text { escuchabay dialogaba con todos. }\end{array}$ & $\begin{array}{l}\text { El pilar para que la interlocución funcione era que se } \\
\text { aceptarán como son y les hacía descubrir que sí podian } \\
\text { cambiar su realidad. }\end{array}$ \\
\hline Rubén Viñán & $\begin{array}{l}\text { Sentía la alegría de compartir en } \\
\text { confianza y escuchar por igual } \\
\text { a todos, como seres humanos } \\
\text { que son, útiles y generadores de } \\
\text { cambio. }\end{array}$ & $\begin{array}{l}\text { La proximidad es la clave para que la interlocución } \\
\text { funcione. Nadie que se sienta lejano puede ser ayudado a } \\
\text { cumplir sus objetivos. }\end{array}$ \\
\hline
\end{tabular}




\begin{tabular}{|l|l|l|}
\hline Pedro Torres & $\begin{array}{l}\text { Recibir y tratar a todos por igual } \\
\text { es una muestra de la forma en la } \\
\text { que se interrelacionaba. No había } \\
\text { distinción entre religiosos y laicos. } \\
\text { Este fue el pilar para conseguir } \\
\text { que la gente se acercara a buscar } \\
\text { la transformación. }\end{array}$ & $\begin{array}{l}\text { Durante la noche, una vez por semana, se organizaban } \\
\text { encuentros de debate sobre la realidad de la sociedad. El } \\
\text { análisis era exhaustivo. }\end{array}$ \\
\hline
\end{tabular}

Fuente: Elaboración propia

\section{Discusión}

Leonidas Proaño usó la comunicación alterativa para el cambio social en las comunidades indígenas de Ecuador, principalmente, y en organizaciones sociales; sus actividadesfueron replicadas en otros países dela región. Su discurso fue contrahegemónico, contestatario, contrapoder y enfrentó la dominación. Evidencia que demuestra lo realizado después de la revisión documental y el análisis crítico del discurso que se reflejan en las tablas de recopilación de datos y que a continuación se comentan y describen en profundidad:

\subsection{Acciones colectivas}

La Tabla 2 distingue las actividades y las clasifica en orden cronológico a partir de actos comunicativos-reflexión-acción colectiva. En los actos comunicativos, fase vinculada con la escucha-diálogo, se identifican hechos como el trabajo con la JOC (1942), viajes (1955), parcelación de tierras (1956), la Granja Escuela Tepeyac (1958), la Misión Andina (1959), Concilio Vaticano II (1962-1965), movilizaciones en Iltús (1971) y la definición del hombre concreto (1974). El mérito para descubrir la realidad y acumular información fue la interrelación con las personas, aguzar el oído y replicar (interlocución) en las comunidades, en su despacho obispal, en talleres y jornadas de capacitación. Los datos sirvieron para la difusión en medios masivos (La Verdad, Mensaje, Jatari Campesino, Jatari y ERPE), conferencias, seminarios y en disertaciones.

La reflexión motivó la interrelación y el cambio de actitud. Se identificaron hechos como la explotación laboral en talleres artesanales y en las haciendas, la marginación y exclusión de quienes no alcanzaban la consideración de seres humanos, tener un espacio de tierra para trabajar y la emergencia por iniciar la formación para contrarrestar la exclusión y definirse como hombres habitantes de un espacio geográfico. Un hecho que acrecentó la comprensión de lo que ocurría fue la muerte del dirigente campesino Lázaro Condo (Hoy y mañana, ERPE, 1974), que significó el punto de inflexión.

La acción colectiva fue multisectorial; se programaron actividades no solo desde la iglesia, sino que organizaciones laicas y de indígenas, como lo demuestran los datos que a continuación se describen. La capacitación obrera en Ibarra, a mitad del siglo XIX, ciudad ubicada al norte de Ecuador, motivó la preparación de los trabajadores de fábricas y del campo. Mientras que el 
"proyecto para incorporar al indio a la vida civilizada" y la parcelación de tierras, preludio de la primera Reforma Agraria ecuatoriana, fueron debatidas en esta fase y ejecutadas (Mensaje, 1956). Y hechos, como la llegada de la Misión Andina (Mensaje, 1959) a 17 comunidades para capacitar en agroecología, medicina preventiva, saneamiento ambiental y vivienda popular; el funcionamiento de la Granja Escuela Tepeyac (Mensaje, 1958) y la participación conciliar de Proaño (Jatari Campesino, 1964) que cambió la estructura del clero, demostraron que la reflexión conduciría a la praxis.

El involucramiento de la gente en acciones colectivas, según Proaño (1974), obligaba a dejar la pasividad y entender que la unidad generaría cambio. La transformación ha sido pensada y desarrollada desde lugares propios (Huergo, 2002), por eso las constantes visitas y actividades a las comunidades.

\subsection{Difusión en medios tradicionales (escritos y hablados)}

La Tabla 3 agrupa las actividades de difusión realizadas en los medios que fundó y en los que dirigió y trabajó. Para fin de la presente investigación se consideraron las propuestas definidas relevantes para la transformación. La preocupación por la marginación de los indígenas fue difundida en el bisemanario La Verdad; por primera vez se pronunció por un tema que una década después motivaría la praxis, hasta su muerte. La reivindicación de la mujer, revista Mensaje (1960), ya que aprender un oficio les alejaría de la circunstancia de ser empleadas domésticas. La palabra hablada fue utilizada para referirse del respeto a la tierra y al ser humano, es el inicio de la agroecología, de la producción verde que se extendió por el continente (Hoy y mañana, ERPE; Jatari). Finalmente, su apresamiento y el de otros 17 obispos del mundo en una jornada de capacitación, alertaron los excesos de la dictadura militar que no toleraba el debate sobre la mejoría de las condiciones de vida (Hoy y mañana, ERPE, 1962).

\subsection{Educación popular}

Como se explica en la Tabla 4, la educación popular fue uno de los motores que movió los procesos de cambio social; la fundación de ERPE en 1962 no representó solamente alfabetización o teleeducación, actividades con las que 18.000 indígenas, en una primera etapa aprendieron a leer y a escribir, sino que fue un ejercicio de comunicación alternativa que les devolvió la voz a quienes no la tenían. En las ediciones finales de la revista Mensaje (1962) se relató sobre la formación de reporteros indígenas y populares, para que lo comunitario sea transmitido mediante las ondas hertzianas, cumpliendo así lo expresado al inicio de este apartado. Sirvió para desarrollar un periodismo especializado en cartas, que contaba los sentires y pareceres de quienes transitaban por la luz de la educación. La fiesta de la lectura, que rompía los moldes tradicionales de los 
aprendizajes en las cuatro asignaturas básicas (Matemáticas, Lenguaje, Ciencias Sociales y Naturales) medía los conocimientos al aire libre, con música y artes.

\subsection{Métodos para la recogida de información}

La Tabla 5 describe los métodos empleados para la recogida de información, interpretación y difusión. Corresponden a las etapas como sacerdote (19361954) y obispo (1954-1985). Durante la primera usó el ver-juzgar-actuar por su proximidad con los trabajadores; lo aprendió durante su formación y con la lectura que llegaban de Europa, sobre todo, de la acción católica desarrollada por Joseph Cardijn, en 1912, como refiere Sanz (2001). En la segunda, empleó la teología de los signos de los tiempos que buscaba la interpretación de estos y cómo incidían en la gente (Silva, 2009), propuesta posconciliar. La IAP que provoca un cambio social desde el estudio de la realidad, la reflexión y la praxis colectiva (Rojas, 2012). La Teoría de la Acción Comunicativa que, desde la perspectiva de Habermas (1976), se basa en identificar los problemas de los sujetos, interactuar con ellos e intervenir para que modifiquen sus condiciones de vida.

\section{Conclusiones}

Sobre la base de los resultados discutidos de los 1.295 contenidos observados y los 72 discursos, se puede afirmar que la presente investigación determinó que los actos comunicativos de Leonidas Proaño tuvieron como basamento la horizontalidad que, con lo alternativo y popular como eje, buscaron la unidad de las individualidades para el cambio social colectivo.

$\mathrm{Su}$ ejercicio permitió organizar, planificar e intervenir acciones de transformación que significaban una contraposición a lo hegemónico y a la dominación que mantenían excluidos a los indígenas en el Ecuador. Su sistema de comunicación sirvió para codificar discursos y acciones para modificar la realidad de los seres humanos, sobre la fortaleza de la escucha-diálogo.

Los resultados respondieron a la pregunta ¿de qué manera la comunicación alternativa de Proaño registró información sobre la realidad sociocultural, la difundió en medios tradicionales (hablados y escritos), y motivó la acción y cambio social de las comunidades indígenas, durante cincuenta años? Los datos de los procesos: acción colectiva, difusión en medios tradicionales, educación popular y metodología para recolección de datos, se desarrollaron durante: viajes, encuentros de indígenas con organizaciones, el uso de los medios masivos (prensa y radio) y educación popular. Todo esto permitió confirmar el objetivo: Identificar la utilización de la comunicación alternativa para la transformación. La información concuerda con elementos comunicativos que consta en los documentos observados en este artículo. 
Las acciones colectivas configuraron momentos clave para la modificación de la realidad, sirvió para acumular datos provenientes del diálogo en asambleas comunitarias con indígenas y representantes de organizaciones. Están vinculadas con la publicación y emisión en medios tradicionales, la educación popular y los métodos.

Observados los datos y efectuada su discusión, puede afirmarse que existe evidencia de la aplicación de la comunicación alternativa que contribuyó a la transformación de los indígenas ecuatorianos con Proaño como inmejorable eslabón en el ámbito de la comunicación social.

\section{Referencias bibliográficas}

Alcántara, L.C.S, Sampaio, C. A. C., \& Uriarte, L. (2018): Experiencia Cooperativa de Mondragón: la educación cooperativa como un proceso de transformación social. CIRIEC-España, Revista de Economía Pública, Social y Cooperativa, 93, 181-209, doi:10.7203/ CIRIEC-E.93.9217

Almanza, L., Mesa, C., Naranjo, S., Soler, S., Ordoñez, M., \& Suárez, M. (2019). Las Tecnologías de la Información y las Comunicaciones: una alternativa a tener en cuenta en la Universidad Ciencias Médicas de Matanzas. Revista Médica Electrónica, 41(3), 775-782. Recuperado de http://scielo.sld.cu/scielo.php?script=sci_arttext\&pi$\mathrm{d}=$ S1684-18242019000300775\&lng=es\&tlng=es

Barranquero, A., \& Sáez, Ch. (2012). Teoría Crítica de la Comunicación Alternativa para el cambio social. El legado de Paulo Freire y Antonio Gramsci en el diálogo norte-sur. Razón y Palabra, N. ${ }^{\circ} 80$, agosto-octubre, 2012. Universidad de los Hemisferios. Recuperado de http://revistarazonypalabra.org/index.php/ryp/article/view/457

Bellini, L. (2009). Palabras de liberación. Quito: Abya-Yala.

Bravo, J. (2011). La rosa de los vientos. Riobamba: Casa de la Cultura.

Bravo, J., Mora, J., \& Galindo, F. (2019). Proaño como pionero de la Investigación Acción Participativa (IAP) en comunidades indígenas. Revista CP, 2019, Vol. 8, ‥ ${ }^{\circ} 17$, pp. 55-76. ISSN 2014-6752. Girona (Catalunya), Universitat de Girona. Recuperado de https://communicationpapers.revistes.udg.edu/communication-papers/article/view/22296/26117

Bravo, J. \& Galindo, F. (2020). El discurso de Mons. Leonidas Proaño como proceso de cambio social en las comunidades indígenas de la región central de Ecuador (Tesis Doctoral). Universidad de Santiago de Compostela, Santiago, España. Recuperado de https://minerva. usc.es/xmlui/handle/10347/23514

Browne-Sartori, Rodrigo, \& Castillo-Hinojosa, Ana María. (2013). Análisis crítico del discurso de la representación intercultural en la prensa chilena. Convergencia, 2o(62), 13-43. Recuperado de http://www.scielo.org.mx/scielo.php?script=sci_arttext\&pi$\mathrm{d}=$ S1405-14352013000200002\&lng=es\&tlng=es

Calderón, D., \& Alvarado, J. (2011). El papel de la entrevista en la investigación sociolingüística. Cuadernos de Lingüística Hispánica, N. ${ }^{\circ}$ 17. Recuperado de https://revistas.uptc. edu.co/index.php/linguistica_hispanica/article/view/423/423

Castillo, D. (1997). Discurso autoritario y comunicación alternativa. Ciudad de México: Coyoacán.

Castro, T. (2017). Revisión y análisis documental para el estado del arte: Imaginarios sociales sobre inclusión educativa. Revista Latinoamericana de Educación Inclusiva, 2017, 11(1), 
183-297. Recuperado de https://www.semanticscholar.org/paper/Revisión-y-Análisis-Documental-para-Estado-del-Castro/36c8eed511c97dc6840df5592049b43b8b40431d

Cepeda, G., Mujica, G., Pilleux, M., \& Poblete, M. (1999). Análisis crítico del discurso en una entrevista semiformal. Estudios filológicos, (34), 73-82. https://dx.doi.org/10.4067/ Soo71-17131999003400006. Recuperado de https://scielo.conicyt.cl/scielo.php?scrip$\mathrm{t}=$ sci_arttext\&pid=So071-17131999003400006

Clauso, A. (1993). Revisión documental. Revista General de Información y Documentación, Vol. 3 (II), 11-19, Edil. Complutense. Madrid.

Corrales, F., \& Hernández, H. (2009). La comunicación alternativa en nuestros días: un acercamiento a los medios de la alternancia y la participación. Razón y Palabra, N. ${ }^{\circ}$ 70, noviembre-enero, 2009. Recuperado de http://www.razonypalabra.org.mx/N/N70/ CORRALES-HERNANDEZ-REVISADO.pdf

De Hoyos, L. (1949). El indigenismo americano. Revista de estudios políticos, ISSN o0487694, N. ․ 45, 194.9, 177-190.

Deliyore-Vega, María del Rocío. (2018). Comunicación alternativa, herramienta para la inclusión social de las personas en condición de discapacidad. Revista Electrónica Educare, 22(1), 271-286. https://dx.doi.org/10.15359/ree.22-1.13.

Feria, H. Matilla, M., \& Mantecón, S. (2020). La entrevista y la encuesta: ¿Métodos o técnicas de indagación empírica? Revista Didáctica y Educación. Vol.11, N. ${ }^{\circ}$ 3. Recuperado de http://revistas.ult.edu.cu/index.php/didascalia/article/view/992/997

Folgueiras, P. (2016). Técnica de recogida de información: La entrevista. Barcelona: Universidad de Barcelona.

Fowler, R. (1985). "Power". Handbook of discourse analysis. Vol. 4. Londres: Academic Press. Freire, P. (1970). Palabras de liberación. Montevideo: Siglo XXI.

Galdón, G. (2002). Teoría y práctica de la documentación informativa. Barcelona: Ariel.

Gómez, M, Deslauriers, J., \& Piedrahita, M. (2010). Cómo hacer tesis de maestría y doctorado: investigación, escritura y publicación. Bogotá: Ecoe.

González Piñeres, N. (2004). El movimiento indígena y sus paradigmas de interpretación. Revista Científica Guillermo de Ockham, Vol. 2, N. ${ }^{\circ}$ 2, julio-diciembre, 139-161. Universidad de San Buenaventura Cali, Colombia. Recuperado de https://www.redalyc.org/ pdf/1053/105317711008.pdf

Habermas, J. (1976). La reconstrucción del materialismo histórico. Madrid: Taurus.

Huergo, Jorge A. (2002). Nuevas aventuras de la perspectiva crítica: la investigación "con" la transformación social. Nómadas (Col) [Internet]. Recuperado de http://www.redalyc. org/articulo.oa?id=10511795100

Kalplún, G. (2019). La comunicación alternativa entre lo digital y lo decolonial. Chasqui. Revista Latinoamericana de Comunicación, N. ${ }^{0}$ 141, agosto-noviembre 2019. Sección Monográfico, 75-94, ISSN 1390-1079 / e-ISSN 1390-924X Ecuador, CIESPAL. Recuperado de https://revistachasqui.org/index.php/chasqui/article/view/4077/3162

Lewis, P. (1995). Los Medios de comunicación alternativos: la conexión de lo mundial con lo local. París: Unesco.

Martín-Pena, D., \& Aguaded, I. (2016). La radio universitaria en España: comunicación alternativa de servicio público para la formación. Comunicación y sociedad, (25), 237-265. Recuperado de http://www.scielo.org.mx/scielo.php?script=sci_arttext\&pi$\mathrm{d}=$ So188-252X2016000100010\&lng=es\&tlng=es

Mendivil, C., Racedo, Y., Meléndez S., \& Rosero, J. (2015). El papel de la Comunicación para el cambio social: empoderamiento y participación en contextos de violencia. Revis- 
ta Encuentros, Universidad Autónoma del Caribe, 13 (1), pp. 11-23. DOI: http://dx.doi. org/10.15665/re.v13i1.345

Monje, C. (2011). Metodología de la investigación cualitativa y cuantitativa. Neiva: Universidad Sur Colombiana.

Olmedo Salar, S. (2014). Comunicología de la liberación, desarrollismo y políticas públicas. Málaga: Kadmos.

Pensa, D., \& Roitman, S. (2005). La comunicación alternativa en la construcción política: Una experiencia de Córdoba. Espacio Abierto, Vol. 14, N. ${ }^{\circ}$, julio-septiembre, 2005, 359-370 Universidad del Zulia Maracaibo, Venezuela. Recuperado de https://produccioncientificaluz.org/index.php/espacio/article/view/1287

Peña, T., \& Pirela, J. (2007). La complejidad del análisis documental. Información, cultura y sociedad: revista del Instituto de Investigaciones Bibliotecológicas, $\mathrm{N} .{ }^{\circ} 16$, enero-junio, 2007, 55-81 Universidad de Buenos Aires, Argentina. Recuperado de https://core.ac.uk/ download/pdf/11889274.pdf

Pérez, J. (2016). Comunicación alternativa: una opción para los jóvenes. Comunicación: estudios venezolanos de comunicación, ISSN 0798-1856, N. ${ }^{\circ} 176$ (4 ${ }^{\circ}$ trimestre), $\underline{2016}$ (Ejemplar dedicado a: Transversalidades), 159-164. Recuperado de https://dialnet. unirioja.es/servlet/articulo? codigo $=6144205$

Proaño, L. (1956). De conversación con mis hijos: la parcelación. Mensaje. Diócesis de Riobamba.

Proaño, L. (1959). De conversación con mis hijos: Horizontes. Mensaje. Diócesis de Riobamba. Proaño, L. (1960). De conversación con mis hijos: El CEAS. Mensaje. Diócesis de Riobamba. Proaño, L. (1974). Concientización, evangelización y política. Salamanca: Sígueme.

Proaño, L. (1976). Evangelio Subversivo. Salamanca: Sígueme.

Proaño, L. (1980). Creo en el hombre y en la comunidad. California: Universidad de California. Proaño, L. (2011). Abriendo surcos indígenas 1. Riobamba: Fondo Documental Diocesano. Proaño, L. (2011). Abriendo surcos indígenas 2. Riobamba: Fondo Documental Diocesano. Rojas, R. (2012). Investigación-acción-participativa. Quito: Universidad Politécnica Salesiana. Sáez, Ch. (2009). Invisibilización de la comunicación alternativa. Revista Latina de Comunicación Social, ISSN-e 1138-5820, ‥ ${ }^{\circ}$ 64, 2009. Recuperado de http://www.revistalatinacs. org/og/art/34_833_44_ULEPICC_16/RLCS_art833.pdf

Sager, F. (2011). Una aproximación al concepto de Comunicación Alternativa. Question/Cuestión, 1(30). Recuperado de https://perio.unlp.edu.ar/ojs/index.php/question/article/ view/1164

Sanz, F. (2001). La Juventud Obrera Cristiana: Un movimiento educativo popular. Hist, educ. 20. Salamanca: Universidad de Salamanca.

Silva, E. (2009). Una teología de los signos de los tiempos latinoamericanos. Validez, límites y porvenir de una hermenéutica teológica del Concilio. Teología y Vida, L (1-2), 41-58. Recuperado de https://scielo.conicyt.cl/scielo.php?script=sci_arttext\&pi$\mathrm{d}=$ Soo49-3449200900010000 5

Simpson M. (1986). Comunicación alternativa y cambio social: América Latina. Ciudad de México: Premia.

Trindade, V. (2016). Técnicas y estrategias en la investigación cualitativa. Buenos Aires: EDULP.

Urra-Medina, E., \& Sandoval-Barrientos, S. (2018). El análisis del discurso crítico en las investigaciones de salud. Enfermería universitaria, 15(2), 199-211. https://doi.org/10.22201/ eneo.23958421e.2018.2.65176. Recuperado de http://www.scielo.org.mx/pdf/eu/ 
v15n2/2395-8421-eu-15-02-199.pdf

Valenzuela, V., Murua, D., \& Poblete, N. (2011). El discurso contrahegemónico y la demanda de una nueva sociedad en las revistas estudiantiles chilenas Claridad (1920) y Bello Público. Lima: Pontificia Universidad Católica de Perú. Recuperado de http://congreso.pucp. edu.pe/alaic2014/wp-content/uploads/2013/o9/GT11-Valenzuela-Murua-Poblete.pdf

Van Dijk, T. (2016). Análisis crítico del discurso. Revista Austral de Ciencias Sociales 30: 203-222, 2016. Recuperado de http://revistas.uach.cl/index.php/racs/article/view/871 